\title{
Renewal of Pavlovian conditioned inhibition
}

\author{
LISA M. FIORI, ROBERT C. BARNET, and RALPH R. MILLER \\ State University of New York, Binghamton, New York
}

\begin{abstract}
Prior research has demonstrated renewal, which is the ability of contextual cues to modulate excitatory responding to a Pavlovian conditioned stimulus (CS). In the present research, conditioned lick suppression in rats was used to examine similar contextual modulation of Pavlovian conditioned inhibition. After Pavlovian conditioned inhibition training with a CS in one context, subjects were exposed to pairings of the CS with an unconditioned stimulus (US) either in the same or in a second context. Results indicated that, when the CS was paired with the US in the second context, the CS retained its inhibitory control over behavior, provided that testing occurred in the context used for inhibition training. However, when the CS-US pairings occurred in the inhibition training context, the CS subsequently proved to be excitatory regardless of where testing occurred. These observations indicate that conditioned inhibition is subject to renewal.
\end{abstract}

In Pavlovian conditioned inhibition training, a subject is presented with two types of trials that occur in an interspersed fashion. On some trials, a conditioned excitor (A) is paired with an unconditioned stimulus (US or + ), and on other trials, the same excitor is paired with the intended inhibitory stimulus $(X)$ in the absence of the US (i.e., $A+/ A X-)$. A summation and/or retardation test is then used to assess the inhibitory response potential of $X$. In a summation test, a previously trained excitor (B) is presented either alone (i.e., B) or in simultaneous compound with the presumed inhibitory conditioned stimulus (i.e., BX). The conditioned stimulus (CS) is viewed as a conditioned inhibitor if the level of responding to the compound of the excitor and presumed inhibitor is lower than the level of responding to the excitor alone. The inhibitory response potential of a stimulus is also suggested if that stimulus passes a retardation test. In a retardation test, slower acquisition of excitatory responding is seen after inhibitor-US pairings than after pairings of an otherwise equivalent noninhibitory stimulus with the same US.

Rescorla and Wagner's (1972) model predicts that the pairing of a previously trained inhibitor with a US results in an accrual of positive associative strength to that CS, thereby abolishing its inhibitory properties. However, a different outcome is seen after a negative patterning procedure, which may be viewed as Pavlovian conditioned inhibition trials $(\mathrm{A}+/ \mathrm{AX}-)$ with $\mathrm{X}+$ pairings interspersed. That is, within a session, two different stimuli are reinforced when presented alone, but not reinforced when pre-

Support of this research was provided by NIMH Grant 33881 and the SUNY-Binghamton Center for Cognitive and Psycholinguistic Sciences. R.C.B. was supported by a Canadian NSERC postgraduate scholarship. Thanks are due Nicholas J. Grahame for assistance in experimental design, James Esposito for assistance in collecting the data, and Robert Cole, Francisco Esmoris-Arranz, and Hua Yin for comments on an earlier version of this manuscript. Requests for reprints should be addressed to R. R. Miller, Department of Psychology, State University of New York, Binghamton, NY 13902-6000. sented in simultaneous compound (i.e., $\mathrm{A}+/ \mathrm{AX}-/ \mathrm{X}+$ ). Under these conditions, $X$ continues to attenuate responding to $A$ (and vice versa) when $X$ is tested in compound with A, despite X's having been paired with the US (see, e.g., Rescorla, Grau, \& Durlach, 1985; see also Pearce \& Wilson, 1991). Because there are different patterns of findings that result from $\mathrm{X}$-US pairings that occur after conditioned inhibition training as opposed to interspersed within conditioned inhibition training, our intention was to more closely examine the features critical to the inhibitor's (X's) maintaining its inhibitory potential after pairings with the US.

Bouton and King (1983) demonstrated the importance of the role of context in modulating behavior. They found that, after excitatory training with a CS in one context and subsequent extinction of responding to that $\mathrm{CS}$ in a different context, excitatory responding was restored, or renewed, when the subject was returned to the excitatory training context. Renewal of excitatory responding following extinction has been demonstrated in both aversive (Bouton \& Bolles, 1979a, 1979b; Bouton \& King, 1983) and appetitive (Bouton \& Peck, 1989) conditioning preparations. Given these data, our expectation was that a context shift between the site of conditioned inhibition training and the site of inhibitor-US trials would allow the target CS to maintain its inhibitory power when tested back in the conditioned inhibition training context. We presented these two session types (A+/AX - in one context and $X+$ in a second context) in an interspersed fashion, since the negative patterning literature suggested that this might facilitate X's simultaneously accruing both inhibitory and excitatory potential. Specifically, this study was designed to determine whether Pavlovian conditioned inhibition, like conditioned excitation, is subject to renewal.

\section{METHOD}

\section{Subjects}

The subjects were 144 naive, 80 - to 120 -day-old, male and female rats of Sprague-Dawley descent. The animals were bred in 
our colony from Holtzman stock (Madison, WI). Body weight ranges were $185-410 \mathrm{~g}$ for males and 175-270 $\mathrm{g}$ for females. Each animal was assigned to one of four groups counterbalanced for sex. All animals were individually housed in wire-mesh cages in a vivarium that was maintained on a 16:8-h light:dark cycle. Experimental manipulations occurred near the midpoint of the light portion of this cycle. Purina Laboratory Chow was freely available in the home cages. One week prior to the initiation of the study, all subjects were progressively deprived of water. By Day 1 of the study, access to water in the home cage was limited to $10 \mathrm{~min} /$ day, which occurred 18-22 $\mathrm{h}$ prior to any treatment scheduled for the following day. All subjects were handled three times per week for $30 \mathrm{sec}$, from the time of weaning until the initiation of the study.

\section{Apparatus}

Two types of enclosures were used. Enclosure $R$ was a clear, rectangular, Plexiglas chamber measuring $22.75 \times 8.25 \times 13 \mathrm{~cm}$ (length $\times$ width $\times$ height). The floor was constructed of stainless steel rods $0.48 \mathrm{~cm}$ in diameter and spaced $1.5 \mathrm{~cm}$ apart center-tocenter. The rods were connected by NE- 2 neon bulbs, which allowed constant-current footshock to be delivered by means of a highvoltage ac circuit in series with a 1.0-M $\Omega$ resistor. Enclosure $R$ could be brightly illuminated by a flashing $(0.5 \mathrm{sec}$ on $/ 0.5 \mathrm{sec}$ off $)$ $25-\mathrm{W}$ (nominal at $120 \mathrm{~V} \mathrm{ac}$ ) incandescent bulb driven at $100 \mathrm{~V}$ ac. Enclosure $\mathrm{R}$ was otherwise dimly illuminated by a $2-\mathrm{W}$ (nominal at $120 \mathrm{~V} \mathrm{ac}$ ) incandescent houselight driven at $56 \mathrm{~V}$ ac. The houselight was turned off whenever the bright flashing light was being presented. Both bulbs were mounted approximately $30 \mathrm{~cm}$ from the center of the enclosure. Six copies of Enclosure R were used, each encased in a separate environmental isolation chest.

Enclosure V was a $30-\mathrm{cm}$-long box in the shape of a vertical truncated $V$. The enclosure was $28 \mathrm{~cm}$ high and $21 \mathrm{~cm}$ wide at the top, narrowing to $5.25 \mathrm{~cm}$ wide at the bottom. The floor and $30-\mathrm{cm}$ long sides were constructed of sheet metal. The floor consisted of two $30-\mathrm{cm}$-long parallel metal plates, each $2 \mathrm{~cm}$ wide, with a 1.25 $\mathrm{cm}$ gap between them. A constant-current footshock could be delivered through the floor of the enclosure. The end walls of the enclosure were black Plexiglas, and the roof was clear Plexiglas. Enclosure V could be brightly illuminated by a flashing $(0.5 \mathrm{sec}$ on $/ 0.5 \mathrm{sec}$ off) $25-\mathrm{W}$ (nominal at $120 \mathrm{~V}$ ac) incandescent bulb driven at $100 \mathrm{~V}$ ac. Enclosure $\mathrm{V}$ was otherwise dimly illuminated by a 7.5-W (nominal at $120 \mathrm{~V}$ ac) incandescent houselight driven at
$56 \mathrm{~V}$ ac. The houselight was turned off whenever the flashing light was being presented. The bulbs were mounted approximately $30 \mathrm{~cm}$ from the center of the animal enclosure. Each of six copies of Enclosure $\mathrm{V}$ was encased in its own environmental isolation chest. Light entered the enclosure primarily by reflection from the roof of the environmental chest. Because of its opaque walls, Enclosure $V$ was illuminated similarly to Enclosure R, despite the presence of brighter light bulbs in Enclosure V.

Enclosures $\mathrm{R}$ and $\mathrm{V}$ could both be equipped with lick tubes that protruded $2.0 \mathrm{~cm}$ from the far end of a cylindrical drinking niche. Each niche was $5 \mathrm{~cm}$ in depth and $4.4 \mathrm{~cm}$ in diameter and was set into one of the narrow walls, $6.5 \mathrm{~cm}$ above the chamber floor. The axis of the niche was perpendicular to the enclosure wall and was left-right centered on the wall. An infrared photobeam, $0.5 \mathrm{~cm}$ in front of the lick tube, was used to detect when the subjects had their heads inserted into the drinking niche.

Treatment and testing occurred in one of two contexts designated Context 1 and Context 2. Within each treatment group, Enclosures $\mathrm{R}$ and $\mathrm{V}$ were counterbalanced with respect to which served as Context 1 and which served as Context 2 . In addition to the previously described differences between Context 1 and 2 , Context 1 was further differentiated by a methyl salicylate odor cue. This was achieved by applying one drop of $100 \%$ methyl salicylate to a small, rectangular block of wood that was placed in each isolation chest housing Context 1 . On training days on which animals were conditioned in both contexts, training was always conducted in Context 2 prior to Context 1 .

Auditory CSs could be presented in Enclosures R and V through three speakers located on each of three interior walls of the environmental chests. The speakers could deliver a white noise $10 \mathrm{~dB}(\mathrm{C})$, re. SPL, above background, a $3000-\mathrm{Hz}$ tone $8 \mathrm{~dB}(\mathrm{C})$ above background, and a train of 6 clicks per second $8 \mathrm{~dB}(\mathrm{C})$ above background. All CS presentations were $30 \mathrm{sec}$ in duration. The auditory background was a 74- $\mathrm{dB}(\mathrm{C})$ ambient sound level created by ventilation fans of the environmental chests. All USs were 1.0-mA footshocks of $0.5 \mathrm{sec}$ duration.

\section{Procedure}

The critical aspects of our procedure are summarized in Figure 1. Subjects were assigned to one of four treatment groups. Group Renewal Experimental (REN-E) was the experimental group of interest. These subjects received inhibition training in one context

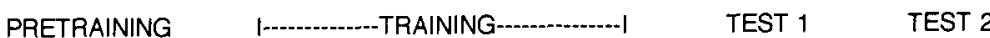

INHIBITION EXCITATION

\begin{tabular}{|c|c|c|c|c|}
\hline REN-C & $(A+/ B+)_{1}$ & $(A+/ A X-)_{1}$ & $(Y+)_{2} \quad(X+)_{1}$ & $\begin{array}{l}(\mathrm{BX})_{1} \\
(\mathrm{~B})_{1}\end{array}$ \\
\hline REN-E & $(A+/ B+)_{1}$ & $(A+I A X-)_{1}$ & $(X+)_{2}(Y+)_{1}$ & $\begin{array}{l}(\mathrm{BX})_{1} \\
(\mathrm{~B})_{1}\end{array}$ \\
\hline $\mathrm{Cl}$ & $(A+/ B+)_{1}$ & $(A+/ A X-)_{1}$ & $\mathrm{HC}$ & $\begin{array}{l}(B X)_{1} \\
(B)_{1}\end{array}$ \\
\hline El & $(A+/ B+)_{1}$ & $(A+/ X-)_{1}$ & $\mathrm{HC}$ & $\begin{array}{l}(\mathrm{BX})_{1} \\
(\mathrm{~B})_{1}\end{array}$ \\
\hline
\end{tabular}

Figure 1. Experiment design. A, training excitor (i.e., light); B, transfer excitor (i.e., clicks); $X$, target CS (i.e., tone or white noise); Y, nontarget CS (i.e., white noise or tone); + , footshock US; -, nonreinforced. Subscripts denote context used: 1, Context 1; 2, Context 2; HC, home cage. Inhibition training occurred on Days 5-8, 10-12, and 14-16, and excitation training occurred on Days 9,13 , and 17 . See text for details. 
and excitation training in a different context. Group Renewal Control (REN-C) received both inhibition training and excitation training in the same context. Group Conditioned Inhibition (CI) received inhibition training only and remained in the home cage during excitation training. This group was designed to provide evidence that conditioned inhibition could be achieved with the present conditioned inhibition training parameters. Group External Inhibition (EI) was intended to control for the possibility that unconditioned effects of the target stimulus $(X)$ might cause a decrement in responding to the transfer excitor (B) when the two cues were compounded.

During the inhibition training sessions, Groups REN-C, REN$\mathrm{E}$, and $\mathrm{CI}$ received conditioned inhibition training in Context 1. This consisted of interspersing trials of the training excitor paired with the US (i.e., $\mathrm{A}+$ ) and the training excitor-target $\mathrm{CS}$ compound (i.e., AX-) without the US. During these sessions, Group El received interspersed trials consisting of the reinforced training excitor (i.e., A+) and the nonreinforced target CS (i.e., $\mathrm{X}-$-).

Excitation training sessions alternated with the conditioned inhibition training sessions in a cyclic fashion. During these excitatory sessions, Group REN-C received reinforced target CS trials (i.e., $\mathrm{X}+)$ in the same context in which conditioned inhibition training occurred (i.e., Context 1) and reinforced nontarget CS trials (i.e., $\mathrm{Y}+$ ) in a distinctly different context (i.e., Context 2). In contrast, Group REN-E received reinforced target CS trials (i.e., $\mathrm{X}+$ ) in the different context (i.e., Context 2) and reinforced nontarget CS trials (i.e., $\mathrm{Y}+$ ) in the inhibition training context (i.e., Context 1). Stimulus $Y$ was introduced to equate between groups the numbers of reinforced trials in each context. Groups CI and EI remained in the home cage (i.e., HC) during these excitation training sessions.

Finally, a summation test was given, in which either the transfer excitor (i.e., B) or the transfer excitor-target CS compound (i.e., BX) was tested in the inhibition training context (i.e., Context 1). On the next day, an excitation test was given, in which the animals previously tested on the transfer excitor alone (i.e., B) were tested on the target CS alone (i.e., X) in Context 2.

Acclimation. Acclimation to the enclosures was conducted on Days 1 and 2 without any CS or US being presented. During each 60-min daily acclimation session, water-filled lick tubes were available. On Day 1 , subjects were acclimated to Context 1 , which would later serve as both the inhibition training context and the summation test context. On Day 2, subjects were acclimated to Context 2, which would later serve as both the excitation training context (for some subjects) and the excitation test context.

Excitatory pretraining. After acclimation, the lick tubes were removed from each chamber. Excitatory pretraining was then conducted on Days 3 and 4 in Context 1 . On each day, every animal received four reinforced presentations of the training excitor (i.e., $\mathrm{A}+$, the excitatory $\mathrm{CS}$ to be used during inhibition training) and four reinforced presentations of the transfer excitor (i.e., B+, the excitor to be used during the summation test). The click train served as the transfer excitor and the bright flashing light served as the training excitor. All CSs in the study were $30 \mathrm{sec}$ in duration. A 1.0-mA, 0.5-sec footshock served as the US, which occurred during the last $0.5 \mathrm{sec}$ of each CS presentation. Intertrial intervals (ITIs) were between 4 and $8 \mathrm{~min}$, with an average of $6 \mathrm{~min}$. Daily session duration was $60 \mathrm{~min}$.

Training. During training, inhibition and excitation conditioning sessions occurred cyclically. Animals were given Pavlovian conditioned inhibition training in Context 1 on Days 5-8, 10-12, and 14-16. During each of these 60-min sessions, animals in Groups REN-C, REN-E, and CI received four reinforced presentations of the training excitor (i.e., $\mathrm{A}+$ ) interspersed with eight nonreinforced presentations of the training excitor in simultaneous compound with the target $\mathrm{CS}$ (i.e., $\mathrm{AX}-$ ). Group $\mathrm{EI}$ received four $A+$ presentations during each daily session and four nonreinforced presentations of the target CS alone (i.e., $\mathrm{X}-$ ) on Day 16 only. The purpose of these Day 16 target CS presentations to Group EI was to ensure that the target CS was not novel for any animal at the time of testing. In order to reduce the likelihood of differential inhibition being accrued to the target CS by Group EI, Stimulus X was not presented to these animals on Days 5-8, 10-12, and 14-15. The target CS was a white noise for half of the subjects in each group and a tone for the other half of the subjects. ITIs between CS presentations for Groups REN-C, REN-E, and CI averaged $4.5 \mathrm{~min}$, with a range of 3-6 min. For Group EI, prior to Day 16, the average ITI was $9 \mathrm{~min}$, with a range of 6-12 min.

Excitation training sessions with the target CS were interspersed among the conditioned inhibition training sessions for Groups REN$\mathrm{C}$ and REN-E. These sessions occurred on Days 9, 13, and 17. During each of these 30-min sessions, Groups REN-C and REN-E received two reinforced presentations of the target CS (i.e., $X+$ ). For Group REN-C, these X+ pairings occurred in Context 1 (the same context as that used during the inhibition training sessions). For Group REN-E, the X+ pairings occurred in Context 2 (a context different from that used during the inhibition training sessions). On the same days as these $X+$ excitation sessions, independent excitation sessions with a nontarget stimulus, $Y$, were conducted. During each of these 30-min sessions, Group REN-C received two reinforced $Y+$ pairings in Context 2 and Group REN-E received two reinforced $\mathrm{Y}+$ pairings in Context 1 . These $\mathrm{X}+$ and $\mathrm{Y}+$ excitation sessions were separated on each day by $2.5 \mathrm{~h}$ and were designed to equate Groups REN-C and REN-E for exposure to signaled shocks in each of the two contexts. The trials occurred at 10 and $20 \mathrm{~min}$ into each session. Stimulus $Y$ was either a tone or a white noise, whichever was not the target CS. Groups CI and EI remained in their home cages during all of these sessions, but did receive equivalent handling.

Reshaping. Following training, the lick tubes were returned to each chamber. Animals were then reexposed to the inhibition training context (i.e., Context 1) on Days 18 and 19 to reestablish a stable baseline rate of licking prior to testing. During each $60-\mathrm{min}$ session, no stimulus was programmed to occur.

Summation test. The potential of Stimulus $X$ to pass a summation test for inhibition was tested in Context 1 (the inhibition training context) on Day 20. Half the animals from each treatment group were tested for suppression of licking in the presence of the transfer excitor alone (i.e., B). The other half were tested for suppression to a simultaneous compound consisting of the transfer excitor and the target CS (i.e., BX). Session duration was $16 \mathrm{~min}$. After completion of the first 5 cumulative seconds of licking, the appropriate test stimulus (i.e., B or BX) was presented to each animal for $15 \mathrm{~min}$. Latencies to complete the first 5 cumulative seconds of licking upon placement in the enclosure and to complete an additional 5 cumulative seconds of licking in the presence of test stimulus were recorded. All test CSs remained on for a fixed duration of $15 \mathrm{~min}$ in order to equate duration of exposure to the test CS, thereby not providing differential treatment that could affect performance on any subsequent test. Any animal that took longer than $60 \mathrm{sec}$ to complete its first 5 cumulative seconds of drinking (i.e., before onset of the test stimulus) was eliminated from the experiment.

Excitation test. On Day 21, the animals that were tested for suppression to the transfer excitor alone (i.e., B) on Day 20 were tested for suppression to the target CS alone (i.e., X). These animals were placed in Context 2 for $16 \mathrm{~min}$. Upon completion of the first $5 \mathrm{cu}$ mulative seconds of licking, the target CS was presented to each animal for $15 \mathrm{~min}$. Pre-CS latencies to complete these first $5 \mathrm{cu}$ mulative seconds of licking and latencies to complete an additional 5 cumulative seconds of licking in the presence of the target CS were recorded. Animals tested on Day 20 with the transfer excitor-target CS compound were not tested for suppression to the target CS on Day 21 because the test on Day 20 likely altered the associative status of the target CS.

One animal from each of Groups REN-C, REN-E, and EI was eliminated from the study prior to testing, because of illness. Additionally, 2 animals from Group EI and 1 from Group CI met the predetermined exclusion criterion for slow drinking prior to $\mathrm{CS}$ onset 
during the summation test and therefore were eliminated from the study. The remaining subjects numbered 34 in Group REN-C, 35 in Group REN-E, 36 in Group CI, and 33 in Group EI.

Suppression latencies often yield distributions with a strong positive skew. In order to better approximate a normal distribution and thereby justify the use of parametric statistics, a log (base 10) transformation was performed on each suppression score. An alpha level of .05 was adopted for all tests of statistical significance.

\section{RESULTS}

Renewal of conditioned inhibition was demonstrated in the subjects that received target CS excitation training outside of the inhibition training context. When the conditioned inhibitor was paired with the US outside of the inhibition training context, that CS retained its inhibitory behavioral control when it was tested in the inhibition training context. In contrast, when the target $\mathrm{CS}$ was reinforced in the same context in which conditioned inhibition training had occurred, the target CS came to act as an excitor regardless of the context in which testing occurred. The following analyses support these conclusions.

\section{Summation Test}

A 4 (treatment: REN-C, REN-E, CI, or EI) $\times 2$ (test condition: B or BX) analysis of variance (ANOVA) of the summation test data (i.e., Day 20 in Context 1) revealed a main effect of treatment $[F(3,130)=5.63]$, a main effect of test condition $[F(1,130)=6.72]$, and an interaction between test condition and treatment $[F(3,130)=4.93]$. Planned comparisons on Day 20 means were conducted using the overall error term from the above analysis.

Group means as a function of test condition for the summation test are shown in Figure 2. Inspection of Figure 2 reveals that the target $\mathrm{CS}$ (i.e., $\mathrm{X}$ ) reduced suppression to the transfer excitor in Groups REN-E and CI $\left[F_{\mathrm{S}}(1,130) \geq\right.$

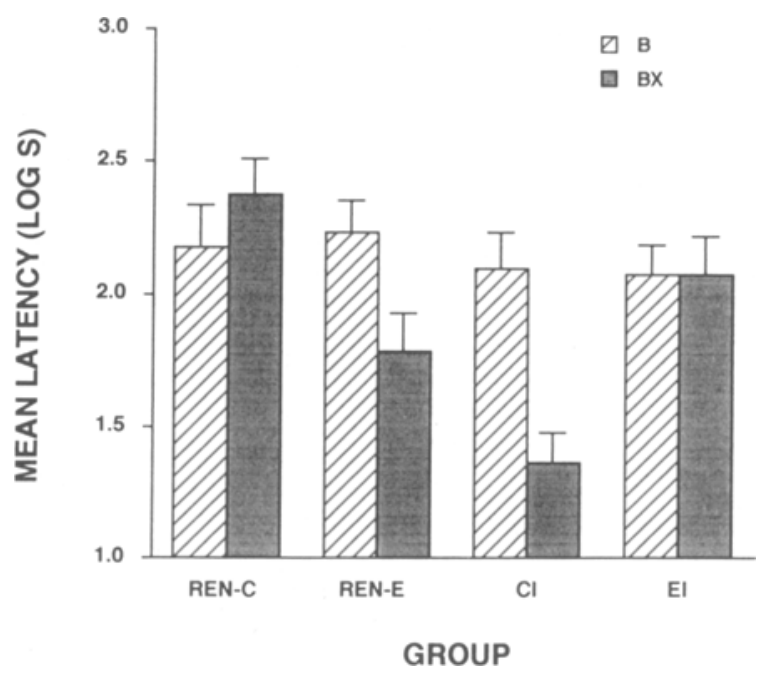

Figure 2. Mean latencies to complete 5 cumulative seconds of licking in the presence of the transfer excitor alone (i.e., B) or the transfer excitor-target CS compound (i.e., BX) in Context 1 on the Day 20 inhibitory summation test. Brackets denote standard errors.

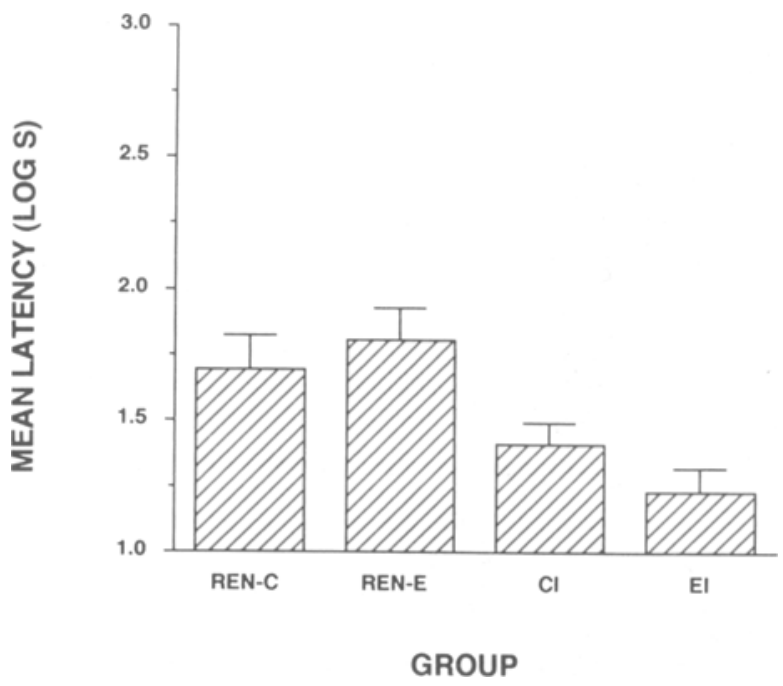

Figure 3. Mean latencies to complete 5 cumulative seconds of licking in the presence of the target CS (tone or noise) in Context 2 on the Day 21 excitation test. Brackets denote standard errors.

5.75]. This attenuated effect of the target CS was not observed in Groups REN-C or EI ( $p s>.10$ ). Thus, the target CS passed a summation test for conditioned inhibition in Groups REN-E and CI, but not in Groups REN$\mathrm{C}$ and EI. The pattern of responding in Group CI indicates that, in the absence of excitation training with $\mathrm{X}$ (and $Y$ ), the Pavlovian conditioned inhibition training of the present experiment was sufficient to establish Stimulus $\mathrm{X}$ as a conditioned inhibitor. When excitation training with Stimulus $X$ occurred in the same context as that used for inhibition training, $X$ lost its ability to function as a conditioned inhibitor (see Group REN-C). However, when excitation training with $\mathrm{X}$ was conducted in a context different from that used for the inhibition training sessions, the inhibitory response potential of $\mathrm{X}$, at least in the inhibition training context, was not eliminated (see Group REN-E). Finally, the failure of Stimulus $X$ to reduce suppression to the transfer excitor for animals in Group EI is important. This finding indicates that the pattern of responding in Groups REN-E and CI cannot be simply attributed to nonassociative factors such as external inhibition (i.e., a decrease in suppression to the transfer excitor due to unconditioned effects of the simultaneously occurring Stimulus $\mathrm{X}$ ).

\section{Excitation Test}

A one-way ANOVA was conducted on the Day 21 scores for suppression to the target CS in Context 2. This analysis revealed an effect of treatment $[F(1,65)=5.73]$. The overall error term from the analysis was used to conduct planned comparisons. Group means are illustrated in Figure 3.

Inspection of Figure 3 suggests that the target CS was more excitatory in groups that received X-US pairings (i.e., Groups REN-C and REN-E) than in groups that had not received X-US pairings (i.e., Groups CI and EI). 
Planned comparisons between groups of the Day $21 \mathrm{ex}-$ citation test revealed that subjects from Group REN-E suppressed more to the target CS (X) than did animals from Groups CI and EI $[F \mathrm{~s}(1,65) \geq 6.68]$. Thus, for Group REN-E, the target CS had become a conditioned excitor as a result of its being paired with the US in Context 2. This occurred even though in Group REN-E Stimulus $X$ had been previously shown to maintain the inhibitory properties it acquired during inhibition training in Context 1. Group REN-C, while exhibiting more suppression than Group EI $\left[F_{\mathrm{S}}(1,65) \geq 8.52\right]$, did not differ significantly from either Group CI or Group REN-E $(p<.075)$. Perhaps this result can be understood in terms of generalization decrement. Group REN-C was tested in a context different from that in which it received the X-US pairings, whereas Group REN-E was tested in the same context in which it received the X-US pairings.

\section{DISCUSSION}

Renewal of conditioned inhibition was observed when excitatory training (i.e., pairings of the conditioned inhibitor with the US) occurred in a context different from that in which conditioned inhibition training had occurred. The present results suggest that, like renewal of conditioned excitation (see, e.g., Bouton \& King, 1983), renewal of conditioned inhibition can be controlled by the particular context in which testing occurs.

The ability of a CS to retain its inhibitory potential despite subsequent pairings of the CS with a US has been previously reported. For example, Pearce and Wilson (1991; see also Rescorla, 1985, for an example with serial inhibition training) reported an appetitive conditioning experiment in which rats were exposed to $X+$ pairings following $A+/ A X-$ training. Subjects reacquired the $\mathrm{A}+/ \mathrm{AX}$ - discrimination more quickly than did control subjects that had previously received $A+/ A Y-$ followed by excitatory conditioning with Stimulus $Y$ (i.e., $Y+$ ). An additional within-subjects experiment involving autoshaping with pigeons consisted of exposing all subjects to $A+/ A X-/ B+/ B Y+$ and then subsequently conditioning Stimulus $X(i . e ., X+$ ). Results indicated that subjects were quicker to reaquire the $\mathrm{A}+/ \mathrm{AX}$ - discrimination than to acquire the $\mathrm{B}+/ \mathrm{BY}-$ discrimination.

The present study demonstrates a similar but slightly different effect. In Pearce and Wilson's (1991) experiments and in our study (i.e., Group REN-E), the inhibitory potential of a CS survived pairings with the US. However, the critical factors underlying the observation of conditioned inhibition differed in the two cases. In Pearce and Wilson's experiments, inhibition and subsequent excitation training with the target CS occurred in the same context. Evidence of the CS retaining inhibitory potential depended on the use of the training excitor that had been used during conditioned inhibition training. When we used the same context for inhibition training and subsequent excitation training (i.e., Group REN-C), we observed no inhibition on a summation test with a transfer excitor that previously had not been used during conditioned inhibition training. This is consistent with the prediction of the Rescorla-Wagner (1972) model that pairing the inhibitor with the US results in the inhibitor losing its inhibitory potential. In contrast, when inhibition training was conducted in one context and excitation training in a different context (i.e., Group REN-E), the CS exhibited inhibitory potential on a summation test. This was observed in the inhibition training context with an independently trained transfer excitor. Thus, the residual inhibitory potential of a CS that was first trained as an inhibitor and then paired with the US was revealed in Pearce and Wilson's experiments by the use of an excitor at test that had previously been used during conditioned inhibition training. In our study, the residual inhibitory potential of the CS was revealed by giving the summation test in a context that had been exclusively used for inhibition training of the CS, with the intervening excitation training of that CS having occurred in a different context.

Although the target CS did not exhibit inhibitory potential in Group REN-C, it did prove inhibitory in Group REN-E. However, the only difference in treatment between Groups REN-C and REN-E was target CS excitatory training was given in the inhibition training context for Group REN-C (i.e., Context 1) and in a different context for Group REN-E (i.e., Context 2). Thus, we can conclude that it was excitation training outside of the inhibition training context that encouraged the survival of the target CS's inhibitory potential in Group REN-E.

Holland (1984) has also presented data demonstrating that a simultaneously trained inhibitor (i.e., $\mathrm{A}+/ \mathrm{AX}-$ ) loses its inhibitory potential after pairings with the US. Following simultaneous inhibition training, Holland paired the target CS with the US (i.e., $\mathrm{X}+$ ) in the same context as that used for inhibition training. In a summation test, after simultaneous inhibition training, $X$ failed to act as a conditioned inhibitor in all circumstances, an observation consistent with the present data (i.e., Group RENC). Then, in a subsequent test, after excitatory responding to $X$ had been extinguished, the inhibitory power of $X$ was examined in a summation test with the training excitor. The result was that $X$ showed recovery of its inhibitory control. The present findings demonstrate that $\mathrm{X}$ can act as an excitor during a test for Pavlovian excitation and still maintain its inhibitory potential when tested in summation, even without extinction of X's excitatory value. However, this outcome appears to require that the target CS-US excitation pairings occur in a context different from that in which conditioned inhibition training has occurred.

Although the present procedures and negative patterning were similar, the configuring explanation that is often invoked (e.g., Rescorla et al., 1985) is not viable with respect to our data. Our summation test used a transfer excitor rather than the excitor used in inhibition training. A configuring explanation could explain low suppression to a compound of Stimulus $X$ with the training excitor (i.e., AX) but not low suppression to a compound of Stimulus $\mathrm{X}$ with an independently trained excitor (i.e., BX). 
Demonstrations of renewal commonly consist of a single phase of excitatory training followed by a single phase of extinction (e.g., Bouton \& Bolles, 1979a, 1979b). The present demonstration of renewal of conditioned inhibition consisted of three cycles of training, in which each cycle included inhibition training followed by excitation training. There are, however, several reports of repeated cycles of training being used in renewal of Pavlovian excitation. One such instance is provided by Bouton and Schwartzentruber (1986), who suggested that a context used for excitation training with a CS and a context used for extinction training with that $\mathrm{CS}$ can act as positive and negative occasion setters, respectively, for the CS. An occasion setter is assumed to modulate responding to a discrete CS independently of the occasion setter's direct association with the US. In Bouton and Schwartzentruber's study, animals were exposed to reinforced presentations of a CS in one context, alternated with nonreinforced presentations of the same CS in a different context. Bouton and Swartzentruber found that subjects rapidly learned to modulate responding to the CS as a function of the particular context in which the CS was presented. Several tests were conducted to rule out the possibility that the contexts themselves had gained either excitatory or inhibitory strength.

By analogy, for Group REN-E, our inhibition training context (Context 1) may have set the occasion for Stimulus $\mathrm{X}$ to act as occasion setter, whereas our excitation training context (Context 2) may have set the occasion for Stimulus $\mathrm{X}$ to act as a conditioned excitor. The present research, however, was not designed to examine the phenomenon of occasion setting by context. Thus, the specific tests for occasion setting were not conducted in this study. Such tests might include the following: (1) testing the ability of the contexts to modulate responding to a different target CS, in that occasion setters transfer only to other CSs that have previously been occasion set; (2) looking at response topography during test trials, in that response topography should reflect the target CS rather than the context; and (3) examining the effects of repeated presentations of Context 2 alone, in that such extinction treatment should degrade Context 2 as a Pavlovian excitor but not impair its value as a positive occasion setter. According to Rescorla (1985), Pavlovian conditioned inhibition is itself a form of occasion setting. If we accept this view, the present research consists of higher order occasion setting (i.e., second-order occasion setting by Context 1 of Stimulus X's first-order occasionsetting properties; see Arnold, Grahame, \& Miller, 1991). Further research is needed to determine whether contextual modulation of conditioned inhibition can be profitably viewed as occasion setting (or higher order occasion setting).

In addition to demonstrations of the renewal phenomenon with animals in the experimental laboratory, there are other instances in which contextual control over behavior has been suggested. For example, Bouton (1988) proposed that the concept of renewal could be applied to the clinical case of exposure therapy for the treatment of anxiety disorders. Specifically, Bouton suggested that fear stimulus (i.e., a phobia) could be more effectively extinguished if the fear-inducing CS was presented several times in a context that was as similar as possible to the context in which the fear was originally acquired as opposed to extinction treatment in a novel context. Additionally, after extinction of a fear-inducing CS, renewal of fear to the CS is less likely if the extinction treatment has occurred in a context similar to that in which the CS is apt to be encountered in the future.

Contextual control of acquired behavior likely takes many diverse forms in everyday life. Behavioral responding in some specific contexts but not in other contexts also likely has considerable adaptive advantage. Taken together with the work of Bouton and his colleagues, the present report suggests that the range of conditions in which acquired behavior is modulated by context may be quite general. Research directed toward isolating that range more precisely will provide an important contribution to our understanding of the environmental control of information processing.

\section{REFERENCES}

Arnold, H. M., Grahame, N. J., \& Miller, R. R. (1991). Higher order occasion setting. Animal Learning \& Behavior, 19, 58-64.

Bouton, M. E. (1988). Context and the ambiguity in the extinction of emotional learning: Implications for exposure therapy. Behavior $R \boldsymbol{e}$ search \& Therapy, 26, 137-149.

Bouton, M. E., \& Bolles, R. C. (1979a). Contextual control of the extinction of conditioned fear. Learning \& Motivation, 10, 445-466.

Bouton, M. E., \& Bolles, R. C. (1979b). Role of conditioned contextual stimuli in reinstatement of extinguished fear. Joumal of Experimental Psychology: Animal Behavior Processes, 5, 368-378.

Bouton, M. E., KING, D. A. (1983). Contextual control of the extinction of conditioned fear: Tests for the associative value of the context. Joumal of Experimental Psychology: Animal Behavior Processes, 9, 248-265.

Bouton, M. E., \& PECK, C. A. (1989). Context effects on conditioning, extinction, and reinstatement in an appetitive conditioning preparation. Animal Learning \& Behavior, 17, 188-198.

Bouton, M. E., \& Schwartzentruber, D. (1986). Analysis of the associative and occasion-setting properties of contexts participating in a Pavlovian discrimination. Journal of Experimental Psychology: Animal Behavior Processes, 12, 333-350.

Holland, P. C. (1984). Differential effects of reinforcement of an inhibitory feature after serial and simultaneous feature negative discrimination training. Journal of Experimental Psychology: Animal Behavior Processes, 10, 461-475.

Pearce, J. M., \& Wilson, P. N. (1991). Failure of excitatory conditioning to extinguish the influence of a conditioned inhibitor. Journal of Experimental Psychology: Animal Behavior Processes, 17, 519-529.

ResCoRla, R. A. (1985). Conditioned inhibition and facilitation. In R. R. Miller \& N. E. Spear (Eds.), Information processing in animals: Conditioned inhibition (pp. 299-326). Hillsdale, NJ: Erlbaum.

Rescorla, R. A., Grau, J. W., \& Durlach, P. J. (1985). Analysis of the unique cue in configural discriminations. Joumal of Experimental Psychology: Animal Behavior Processes, 11, 356-366.

Rescorla, R. A., \& Wagner, A. R. (1972). A theory of Pavlovian conditioning: Variations in the effectiveness of reinforcement and nonreinforcement. In A. H. Black \& W. F. Prokasy (Eds.), Classical conditioning II: Current research \& theory (pp. 64-99). New York: Appleton-Century-Crofts.

(Manuscript received December 8, 1992; revision accepted for publication July 12 , 1993.) 